\begin{tabular}{|c|c|c|}
\hline $\begin{array}{l}\text { PKS } \\
\text { PUBLIC } \\
\text { KNOLLEDEGE } \\
\text { PROECC }\end{array}$ & $\begin{array}{c}\text { Revista de GEOGRAFIA } \\
\text { (RECIFE) } \\
\text { http://www.revistaufpe.br/revistageografia }\end{array}$ & 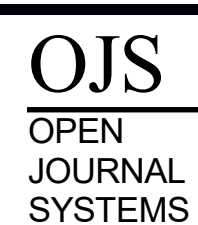 \\
\hline
\end{tabular}

\title{
CARTOGRAFIAS PARTICIPATIVAS: LEVANTAMENTO DE PESQUISAS JUNTO A PROGRAMAS DE PÓS-GRADUAÇÃO EM GEOGRAFIA DO NORDESTE DO BRASIL (2017)
}

\author{
Ana Betânia S. Martins ${ }^{1}$, Tiane A. de Paiva e Souza ${ }^{2}$ \\ ${ }^{1}$ Doutoranda em Geografia na Universidade Federal de Pernambuco e membro do LECgeo-UFPE. Email: \\ anabetania@yahoo.com.br \\ ${ }^{2}$ Geógrafa,LECgeo/UFPE,LACC/UPE.Email: souzatiane@gmail.com
}

Artigo recebido em 28/08/2017 e aceito em 09/10/2017

\begin{abstract}
RESUMO
Este artigo é parte do levantamento bibliográfico realizado para uma pesquisa de doutorado em curso sobre o uso do mapeamento participativo na preservação do patrimônio cultural. Para tanto, nesta etapa da investigação procurou-se compreender como essa temática da cartografia/mapeamento participativo vem sendo estudada pela Geografia, com base na contribuição das pesquisas desenvolvida no nordeste brasileiro, região de interesse deste estudo. Desse modo, como procedimento metodológico optou-se pelo levantamento de teses e dissertações defendidas junto aos programas de pós-graduação em Geografia das universidades públicas do nordeste do país. $\mathrm{O}$ artigo está dividido em três partes: primeiramente, discorre-se brevemente sobre a origem do mapeamento participativo enquanto uma metodologia de produção de conhecimento cartográfico dentro das ciências humanas; na segunda parte, apresenta-se o resultado do levantamento das pesquisas em nível de pós-graduação no campo da Geografia desde o ano 2000, destacando o quantitativo de teses e dissertações produzidas bem como o perfil dessas pesquisas, respectivos programas de pós-graduação, professores orientadores e contextos estudados, bem como grupos sociais enfocados, territórios identificados e demais instituições envolvidas, como ONGs e associações. Na última parte, apresentamos as considerações finais acerca do levantamento agregando reflexões sobre o uso das cartografias participativas na pesquisa geográfica.
\end{abstract}

Palavras-chaves: Cartografia Participativa. Levantamento bibliográfico. Pós-graduação. Geografia.

\section{PARTICIPATORY CARTOGRAPHIES: SURVEY OF RESEARCHES CONNECTED TO GRADUATE PROGRAMS IN GEOGRAPHY IN NORTHEAST OF BRAZIL} (2017)

\begin{abstract}
This paper is part of a bibliographical survey applied for an ongoing doctoral research on the use of participatory mapping in the preservation of cultural heritage. At that moment of investigation, it was sought to understand how this issue of participatory cartography / mapping has been studied by Geography, based on the contribution of the researches developed in the Brazilian northeast, region of interest of this study Thus, as a methodological procedure, it was chosen a survey of theses and dissertations presented in graduate programs in Geography, at public universities in northeastern Brazil. The article has three parts: firstly, a brief approach on the origin of participatory mapping as a methodology for cartographic knowledge production within Human Sciences; secondly, the results of the graduate research in the field of Geography $\square$ taking into account researches since year $2000 \square$ are presented, highlighting the quantitative of theses and dissertations produced as well as the profile of these researches, respective graduate programs, professors and contexts studied; in addition social groups, identified territories and other institutions involved, such as NGOs and associations are emphasized. Finally, the final considerations are presented, including reflections on the use of participatory cartographies in geographic researches.
\end{abstract}

Keywords: Participatory cartography. Bibliographical survey. Graduate programs. Geography. 


\section{INTRODUÇ̃̃O}

A partir da renovação da cartografia na década de 1970 e, mais recentemente, com o incremento na facilidade de acesso às ferramentas digitais de confecção de mapas, o mapeamento participativo passa a ser valorizado como uma opção metodológica para trabalhos desenvolvidos na academia e nos órgãos de gestão, sendo cada vez mais utilizado em contextos como unidades de conservação e terras indígenas, nos quais a percepção da paisagem e dos territórios pelos seus usuários e habitantes é francamente reconhecida como elemento fundamental para que o planejamento das atividades econômicas e culturais possa garantir a sustentabilidade dos próprios territórios e das organizações sociais referentes a estes.

Por outro lado, em alguns campos de atuação o uso dessa abordagem participativa de mapeamentos ainda é recente como revelou o levantamento documental sobre a utilização da cartografia participativa como ferramenta no campo técnico da preservação do patrimônio cultural oficial, pelo IPHAN, no Brasil, realizado no âmbito da investigação doutoral em andamento ${ }^{1}$. Desse modo, para melhor compreender o uso desses mapeamentos nas políticas patrimoniais, a partir do ponto de vista geográfico, faz-se necessário realizar uma revisão de literatura sobre como essa temática da cartografia participativa vem sendo estudada e apropriada pelas pesquisas em Geografia, com especial atenção para a região ado Nordeste brasileiro, na qual se insere nosso objeto de trabalho.

Nesse sentido, este trabalho apresenta o levantamento de teses e dissertações defendidas junto aos programas de pós-graduação em Geografia das universidades públicas do Nordeste do país, afim de visualizar o panorama das pesquisas na área e com isso situar a problemática do uso do mapeamento participativo para a gestão e preservação do patrimônio cultural, nosso objeto.

$\mathrm{O}$ artigo está dividido em três partes: primeiramente, discorre-se brevemente sobre a origem do mapeamento participativo enquanto uma metodologia de produção de conhecimento cartográfico dentro das ciências humanas, em especial no Brasil desde a década de 2000, momento em que esta perspectiva de cartografia desponta através, não só da adoção desta prática na gestão de unidades de conservação, mas também a partir da criação de

\footnotetext{
1 Este artigo é parte da pesquisa mais ampla que busca analisar o mapeamento participativo como instrumento de gestão da preservação do patrimônio cultural em Recife. Realizamos uma primeira aproximação sobre o panorama de utilização dessa metodologia no campo da gestão do patrimônio cultural apresentado por Ana B. Martins em comunicação oral "Contribuições da cartografia participativa na identificação do patrimônio cultural”no XII Simpósio Internacional sobre Espaço e Cultura (NEPEC/UERJ) em 2016. 
projetos como o Nova Cartografia Social da Amazônia ${ }^{2}$ cujas pesquisas fomentaram o interesse no tema. Neste momento, é lançado também o livro Cartografias sociais e território (2008) fruto de um projeto de pesquisa do Instituto de Pesquisa e Planejamento Urbano e Regional (IPPUR-UFRJ) que se propôs levantar e analisar experiências brasileiras nesta áea. Essa obra de alcance nacional, bem como as conquistas de direitos sociais pelas populações envolvidas nos mapeamentos têm contribuído para reforçar e difundir essas cartografias.

$\mathrm{Na}$ segunda parte, apresentamos o resultado do levantamento dos trabalhos de pesquisa em nível de pós-graduação no campo da Geografia desde o ano 2000, destacando o quantitativo produzido bem como apontando o perfil dessas pesquisas, os programas de pósgraduação e instituições de pesquisa associadas, quais os contextos estudados, grupos sociais enfocados, territórios identificados e instituições envolvidas.

$\mathrm{Na}$ última parte, apresentamos as considerações finais acerca do levantamento agregando reflexões sobre o uso das cartografias participativas na pesquisa geográfica.

\section{REFERENCIAL TEÓRICO: BREVE CONTEXTUALIZAÇÃO HISTÓRICA SOBRE A EXPANSÃO DA CARTOGRAFIA PARTICIPATIVA NO BRASIL E NO MUNDO}

A Cartografia Participativa tem se caracterizado de maneira geral pela inclusão dos usuários não especializados na produção de mapas oficiais ou outros produtos cartográficos no processo de produção da informação cartográfica, trazendo à luz o debate sobre a questão “quem mapeia quem?”. (ACSERALD, 2008) e sobre participação social na produção de geoinformação sobre os territórios, conforme bem resumem Acserald \& Viégas (2013) ao apresentar um balanço sobre as experiências brasileiras identificadas por suas pesquisas até aquele momento:

\footnotetext{
As experiências de Cartografia Social [participativa] formam um campo em constante construção que vem, nos últimos 15 anos, promovendo a relativização do sentido oficial de se construir mapas e contribuindo para a ressamantização do termo cartografia atualmente em jogo. (...) Apesar de suas distinções conceituas e metodológicas, a cartografia social pode ser entendida como a apropriação de
}

\footnotetext{
${ }^{2}$ É sabido que a ideia original do PNCSA foi lançada ainda no final da década de 1990, a partir da pesquisa de seu coordenador Alfredo Wagner Berno de Almeida sobre as populações impactadas pelo projeto Grande Carajás no Sudeste Paraense; No entanto, aqui está se tratando do momento de projeção nacional da Cartografia Social e da reverberação dos resultados das pesquisas e ações de cunho político-administrativo como demarcação de terras e reconhecimento de direitos culturais dos povos cujos territórios foram cartografados por esta metodologia. 
técnicas e modos de representação cartográficos modernos por grupos sociais historicamente excluídos dos processos de tomada de decisão" (Acserald; Viégas, 2013, p.16-17)

Tecnicamente, tem se diferenciado da chamada Cartografia Tradicional ou Clássica no que se refere a uma visão menos rígida sobre a escolha dos elementos dos mapas como escala de representação, simbologias e cores para construção de legendas que não seguem necessariamente todos os padrões pré-estabelecidos pelas convenções oficiais de cartografia como a Comissão Nacional de Cartografia no Brasil (CONCAR), mas a formulação desse elementos parte da apropriação de simbologias coerentes aos conteúdos propostos pelos usuários dos mapas, visando, tanto uma boa comunicação com os grupos participantes do mapeamento.

De fato, conforme sintetizado recentemente por Landin Neto et al (2016) em um quadro comparativo entre a Cartografia social e a denominada pelos autores de "Cartografia convencional" as principais diferenças então na adoção do método participativo e qualitativo, bem como na clareza da posição política dos mapeamentos que não se propõem neutros como faz historicamente a abordagem convencional (LANDIM NETO et al, 2016, p. 61-62)

De acordo com Acserald e Coli (2008:14), o movimento denominado por eles como “disseminação de mapas participativos" no âmbito internacional tem como marco temporal o início dos anos 1990, sendo que as primeiras iniciativas de que se tem notícia se deram ainda no final da década de 1970 em áreas indígenas do Canadá, junto a populações esquimós (Inuit). A partir de então, o uso dessa metodologia foi progressivamente adotado junto a instituto de pesquisas e de políticas públicas na América do Norte, onde tal prática de cartografia tem sido denominada de participatory mapping, community-based mapping, Public Participation Information Systems PPGIS, Public Geographic Information System $(P G I S)$, para dar exemplos mais utilizados. Embora a pluralidade de denominações geralmente guarde diferentes abordagens e filosofias, o importante a ressaltar, por enquanto, é o crescente apelo a formas não-autoritárias de cartografia.

No Brasil, esse movimento de utilização de mapeamento participativo junto a metodologias de ações de políticas públicas também ocorre a partir de 1990, e está ligado radicalmente à criação de áreas protegidas como as unidades de conservação do tipo reservas extrativistas e de manejo florestal na Amazônia, bem como a construção de seus instrumentos de gestão - os planos de manejo. Relaciona-se também com a construção dos Planos Diretores municipais, que diante das diretrizes colocadas pela legislação urbanística recente, 
em especial após a promulgação da lei do Estatuto da Cidade, são documentos que tem como princípio uma gestão urbana democrática que apregoam a importância de decisões políticas serem mais dialogadas com a sociedade (ACSERALD e COLI, 2008: 24).

De acordo ainda com Acserald e Coli (op cit, p. 24-25), com base no levantamento realizado por meio do projeto "Experiências em Cartografia Social” do IPPUR/UFRJ, entre 1992 até 2008 já havia cerca de 120 projetos de mapeamento desenvolvidos sob a ótica participativa, nos quais era possível observar uma composição variada de atores participantes como ONGs, organismos de cooperação internacional, como a fundação FORD, organizações sociais, como associações indígenas, quilombolas, movimentos de trabalhadores assentados no campo e até associação de moradores urbanos.

Isso denota que a cartografia participativa é um instrumento centrado na contemplação das demandas dos grupos sociais sobre seus territórios e busca o reconhecimento de formas próprias de conhecer e nomear o espaço, que em geral não são consideradas ou têm menor visibilidade nos mapeamentos oficiais. Em suma, o mapeamento participativo seria "aquele que reconhece o conhecimento espacial e ambiental de populações locais e os insere em modelos mais convencionais do conhecimento" (HERLIHI E KNAPP, 2003 apud ACSERALD, 2008)

Ao situar a emergência da cartografia participativa no desenvolvimento da história da Cartografia, nota-se que o desenvolvimento dessas metodologias foi propiciado por uma conjuntura tecnológica desenhada ainda na década de 1970 e 1980, momento em que a construção e difusão das tecnologias digitais e da internet concorreu positivamente para a passagem definitiva da cartografia analógica para a digital, pois gerou a diminuição dos custos de sistemas computacionais voltados a produção cartográfica e dos equipamentos geotécnicos como o GPS, bússolas, e os Sistemas de Informações Geográfica - SIG (TAYLOR, 1998).

Tal facilidade de acesso às tecnologias de mapeamento permitiu a manipulação de informações cartográficas e mesmo a produção de mapas por leigos, com destaque, mais recentemente, para as plataformas de mapeamento gratuitas disponíveis na internet que disponibilizam bases cartográficas, opções de inserção de marcadores de localização (ponto, linha ou polígono) e permitem a geração de mapas básicos em diferentes escalas conforme o propósito do usuário. ${ }^{3}$ Esse novo quadro tecnológico e informacional impôs o fato de que a

3 Como exemplo podemos citar o sites da Google Maps, MapSource e de instituições públicas como o Ministério do Meio Ambiente- MMA e o Instituto Nacional de Colonização e Reforma Agrária INCRA(I3Geo). 
produção cartográfica não estaria necessariamente restrita a técnicos da área da Cartografia, mas poderia também ser realizada com a participação dos grupos sociais interessados na leitura, apropriação e uso de seu conteúdo (TAYLOR, 1998; FERREIRA et al., 2008).

A percepção dessa conjuntura pelos estudiosos do campo da Cartografia como Taylor (1998), Monmonier (1996), Crampton \& Krygier (2006); Brian Harley (2009, 1991, 1989) foi interpretada como um momento de necessária revisão crítica do aporte teórico e conceitual da própria disciplina cartográfica, bem como de abertura ao diálogo com campos do saber outrora apartados como a História, Ciência Política e a Antropologia. Esses e outros autores foram importantes para o questionamento das bases da Cartografia tradicionalmente desenvolvida até aquele momento, a qual se atribuía o status de verdade e precisão científica. A partir daí lançou-se uma nova linha de trabalhos acadêmicos que se interessam pela compreensão do contexto social e político da produção da informação cartográfica, bem como pela dimensão política da relação entre técnicos e usuários nesse processo (GIRARDI, 2011).

A partir desse breve preâmbulo, como situar o diálogo da Geografia com essa conjuntura atual de produção da Cartografia? A reflexão sobre a produção cartográfica pela Geografia já foi abordada em pesquisas anteriores, como de Matias (1996; 2001), Fonseca (2004); Souza e Katuta (2011), Girardi (2011), para citar alguns autores que discutem como tem se dado a prática da Cartografia aplicada a pensamento e ao ensino de Geografia. Entre estes, é amplamente aceita a ideia de que cabe aos Geógrafos se debruçarem sobre a cartografia não só como técnica mas como linguagem; Da mesma forma, é comum o entendimento de que fazer cartografia na geografia é diferente do uso das técnicas cartográficas ligadas às engenharias e ciências naturais, dado que está embutida a necessidade geográfica de pensar sobre o espaço representado.

De fato, a partir dos anos 2000, observa-se uma retomada e expansão da cartografia e tecnologias associadas dentro da geografia brasileira, que já fora apontado remotamente por Matias (1996). Um indicador dessa retomada é a introdução de disciplinas de geotecnologias nos currículos dos cursos de graduação em Licenciatura e bacharelado em Geografia. Outro seria a crescente publicação de artigos na área das geotecnologias aplicadas a Geografia como o sensoriamento remoto por exemplo (ROSA, 2005; Luchiari et all, 2005; Panizza e Fonseca, 2011).

No que se refere especificamente ao âmbito das Cartografias participativas, começam também a surgir trabalhos de Geografia que lançam mão de metodologias participativas na elaboração de seus mapeamentos. Conforme apontado por Costa (2016) bem como , acredita- 
se que a contribuição direta das comunidades pesquisadas nos mapeamentos em campo inclusive com a adoção dos termos e simbologias por eles propostas, têm gerado reflexões teóricas sobre as formas e se trabalhar os temas de pesquisas geográfica, dando maior visibilidade à maneira de interpretação do território por povos e comunidades.

Portanto, com a presente revisão, busca-se compreender melhor como as pesquisas em nível de pós-graduação em Geografia tem estudado e contribuído para pensar especificamente a questão da cartografia participativa e com isso discutir sobre o que diz a pesquisa geográfica recente sobre esta abordagem cartográfica.

\section{METODOLOGIA DO LEVANTAMENTO}

O universo desta pesquisa constitui-se em teses e dissertações (defendidas até 2017) que versem sobrea cartografia ou o mapeamento participativo, ou, ao menos, apresentam entre seus procedimentos metodológicos e/ou assuntos relacionados ao trabalho indicados pelas palavras-chave utilizadas como critérios de busca e descritas a seguir.

Foram selecionados como mecanismo de busca bancos de dados nacionais de acesso livre e online, sendo eles: os repositórios institucionais de teses e dissertações das universidades públicas do Nordeste do país; as plataformas de pesquisa científica oficiais (criadas e mantidas pelo Instituto Brasileiro de Informação em Ciência e Tecnologia IBCT) disponíveis online como o Portal brasileiro de publicações científicas em acesso aberto (<oasisbr.ibict.br $>$ ) e a Biblioteca Digital Brasileira de Teses e Dissertações (<bdtd.ibict.br $>$ ), bem como site de busca Google Acadêmico e as listas de teses e dissertações defendidas disponibilizadas pelos próprios programas de pós-graduação em Geografia, como se deu no caso da Universidade Estadual do Ceará (UECE).

\begin{tabular}{|c|c|}
\hline \multicolumn{2}{|c|}{ Instituições pesquisadas e respectivas bases de dados utilizadas como fontes } \\
\hline $\begin{array}{l}\text { UFPE - Universidade Federal de } \\
\text { Pernambuco } \\
\text { http://www.repositorio.ufpe.br/ } \\
\text { UFPB - Universidade Federal da Paraíba } \\
\text { http://rei.biblioteca.ufpb.br/jspui/ } \\
\text { UFRN - Universidade Federal do Rio } \\
\text { Grande do Norte }\end{array}$ & $\begin{array}{l}\text { UFBA - Universidade Federal da Bahia } \\
\text { https://repositorio.ufba.br/ri/ } \\
\text { UEFS - Universidade Estadual de Feira de Santana } \\
\quad \underline{\text { http://tede2.uefs.br:8080/ }} \\
\text { UFS - Universidade Federal de Sergipe } \\
\quad \underline{\text { https://ri.ufs.br/ }}\end{array}$ \\
\hline
\end{tabular}


Revista de Geografia (Recife) V. 35, No. 1 (especial), 2018

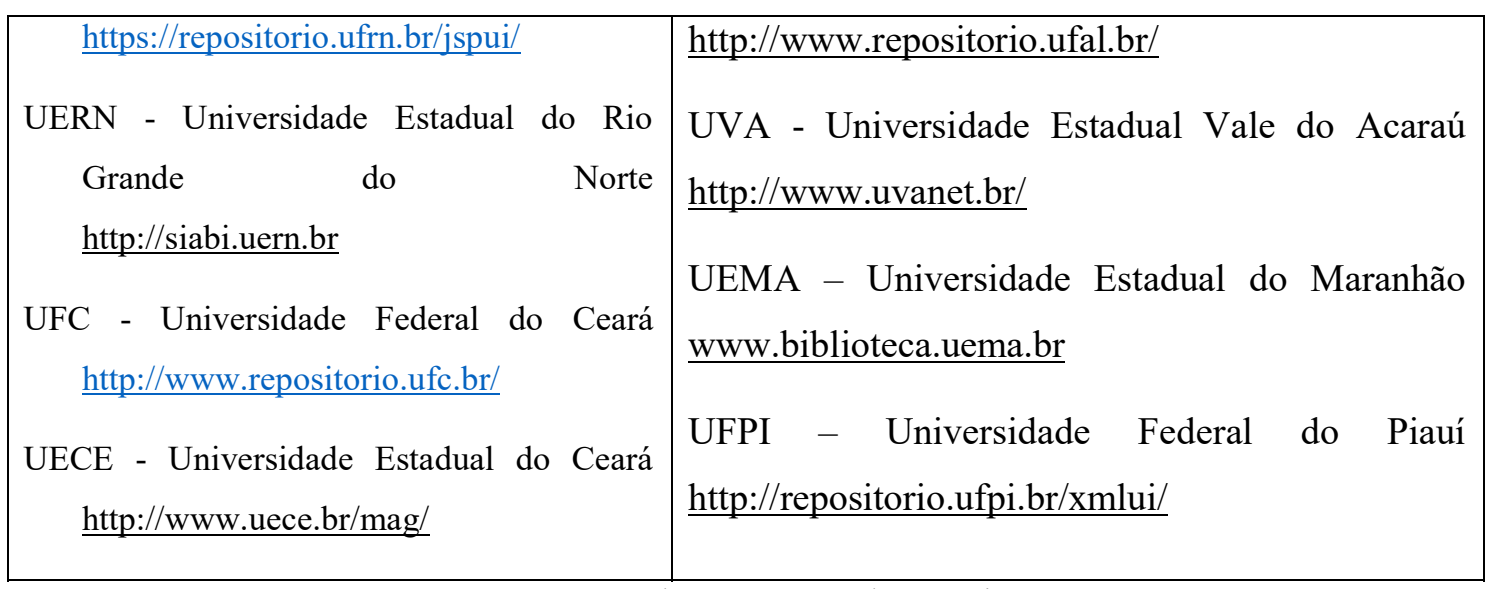

Quadro 1 - Fontes da pesquisa

Para atender ao recorte pesquisado, utilizou-se como palavras-chave/ tags as expressões: mapeamento participativo, mapeamento colaborativo, cartografia participativa, cartografia social, mapa e cartografia. Nessa busca as expressões utilizadas poderiam estar contidas tanto no título, quanto no assunto ou conteúdo do trabalho. Com esses critérios de busca, incluiu-se também trabalhos desenvolvidos em outros programas de pós-graduação além dos de Geografia, como aqueles intitulados Programas em Desenvolvimento e Meio Ambiente (PRODEMA), Programa de Ciências Geodésicas e programas de Planejamento Urbano Regional, mas que, são concernentes a esta pesquisa, pois foram desenvolvidos na chamada "Grande Área" de Geografia, conforme classificação oficial das bases pesquisadas.

Vale ressaltar que se procurou fazer uma revisão ampla de trabalhos acadêmicos do tipo tese e dissertação que foi possível por meio dos mecanismos de busca online disponibilizados pelas instituições de origem e pelas bases de pesquisa supracitadas, obedecendo aos critérios estabelecidos. No entanto, sabe-se que podem haver trabalhos os quais não puderam ser acessados e que escapam a este levantamento por motivos como a sua não disponibilização junto aos repositórios digitais oficiais de teses e dissertações e as dificuldades ou falhas inerentes ao trabalho com alguns mecanismos de busca.

\section{RESULTADOS}

O levantamento junto às bases permitiu chegar-se a um quantitativo de teses e dissertações que têm como parte de seu conteúdo, seja no tema, na metodologia, ou assunto correlato, a cartografia/mapeamento participativo.

Dentre os trabalhos defendidos nas 13 instituições pesquisadas, foram encontradas 10 pesquisas que envolveram o tema aqui em foco, sendo 9 dissertações e 1 tese de doutorado, sistematizadas no quadro a seguir com o respectivo programa e instituição indicado. 


\begin{tabular}{|c|c|c|}
\hline & Título & Programa de Pós-Graduação/Universidade \\
\hline 1 & $\begin{array}{l}\text { A elaboração de documentos cartográficos sob a ótica } \\
\text { do mapeamento participativo }\end{array}$ & Mestrado em Ciências geodésicas/UFPE \\
\hline 2 & $\begin{array}{l}\text { Mudanças e permanências na paisagem do sítio de } \\
\text { Igarassu/PE }\end{array}$ & Mestrado em Desenvolvimento Urbano/UFPE \\
\hline 3 & $\begin{array}{l}\text { Cartografia social: instrumento de luta e resistência no } \\
\text { enfrentamento dos problemas socioambientais na } \\
\text { reserva extrativista marinha da prainha do Canto } \\
\text { verde, Beberibe- Ceará }\end{array}$ & Mestrado em Geografia/UFC \\
\hline 4 & $\begin{array}{l}\text { Parques eólicos e comunidades tradicionais no } \\
\text { nordeste brasileiro: estudo de caso da comunidade de } \\
\text { Xavier, litoral oeste do Ceará, por meio da abordagem } \\
\text { ecológica/participativa }\end{array}$ & Doutorado em Geografia/UFC \\
\hline 5 & $\begin{array}{l}\text { Por uma geografia da (in)visibilidade: cartografia } \\
\text { social e luta pelo reconhecimento indígena na } \\
\text { Província de Buenos Aires/Argentina }\end{array}$ & Mestrado em Geografia/UFRN \\
\hline 6 & $\begin{array}{l}\text { Atores sociais e política ambiental urbana do } \\
\text { Município de Mossoró/RN pelo prisma das } \\
\text { cartografias sociais analíticas }\end{array}$ & $\begin{array}{l}\text { Mestrado em Meio } \quad \text { Ambiente } \\
\text { Desenvolvimento/UFRN }\end{array}$ \\
\hline 7 & $\begin{array}{l}\text { Moradia e habitabilidade no bairro de Pirajá no } \\
\text { contexto da produção do espaço urbano periférico da } \\
\text { cidade de Salvador- BA }\end{array}$ & Mestrado em Geografia/UFBA \\
\hline 8 & $\begin{array}{l}\text { A etnoecologia de pescadoras e as políticas públicas } \\
\text { em Bom Jesus dos Pobres, Saubara-BA }\end{array}$ & $\begin{array}{lll}\text { Mestrado Planejamento } & \text { Territorial } \\
\text { (PLANTERR)/UEFS } & \end{array}$ \\
\hline 9 & $\begin{array}{l}\text { Cartografia participativa e planejamento urbano: } \\
\text { experiências de práticas colaborativas no ambiente } \\
\text { escolar em Campos Sales, Ceará }\end{array}$ & $\begin{array}{l}\text { Mestrado em Geografia/ UVA Sobral/Ceará - } \\
\text { MAG) }\end{array}$ \\
\hline 10 & Visões cartográficas de Itabaiana- SE & $\begin{array}{l}\text { Mestrado em Desenvolvimento e } \\
\text { ambiente/UFS }\end{array}$ \\
\hline
\end{tabular}

Quadro 2 - Teses e dissertações levantadas

O resultado da busca confirma nossa ideia inicial de que se trata de uma produção pouco numerosa e relativamente recente, tendo em vista que o primeiro trabalho nesta área foi 
uma dissertação defendida em 2008, na UFPE. O ano 2016 foi o que concentrou mais trabalhos defendidos na área: duas dissertações e uma tese.

\section{Quantidade de trabalhos defendidos por ano}

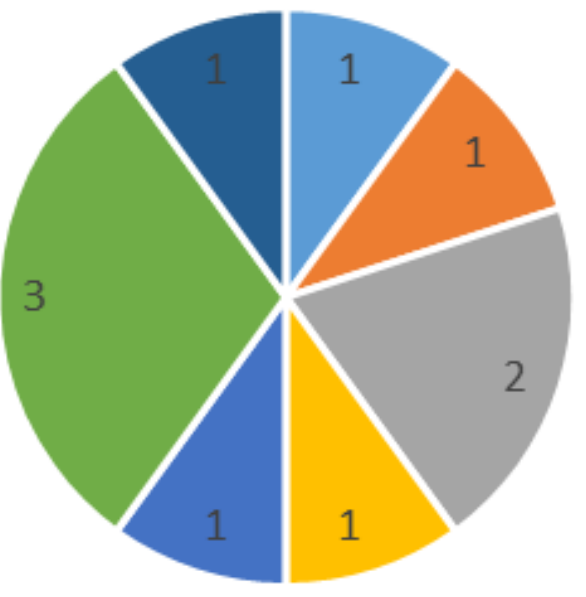

- 2008

- 2011

- 2012

$=2014$

- 2015

- 2016

- 2017

A distribuição dos trabalhos por programa de pós-graduação foi relativamente equilibrada, o que significa que se identificou, ao menos, uma pesquisa sobre mapeamento participativo para cada programa que apresentou resultado positivo.

Do universo de programas de pós-graduação em Geografia pesquisados, 4 instituições não apresentaram em suas listas de trabalhos defendidos e/ou nos repositórios institucionais algum trabalho que tenha como ferramenta ou tema o mapeamento participativo, a saber: UEMA, UERN, UFAL, UFS. No repositório da UFPE identificou-se dois trabalhos envolvendo o mapeamento participativo, não desenvolvidos no programa de Pós em Geografia: um foi defendido junto ao programa de Ciências Geodésicas e outro em Planejamento urbano.

Por outro lado, o Programa de pós-graduação em Geografia da UFC apresentou dois trabalhos diretamente relacionados ao campo da cartografia participativa, constituindo-se em uma tese (a única encontrada por este levantamento) e uma dissertação. O destaque da UFC na produção sobre o tema está ligado ao trabalho do Laboratório de Cartografia do departamento de Geografia daquela instituição LaboCArt), que tem desenvolvido vários 
projetos ${ }^{4}$ coordenados pela profa. Adriane Gorayeb, que relacionam a cartografia participativa com a análise de impactos ambientais de empreendimentos nas paisagens, especialmente àquelas localizadas em ambientes costeiros do estado do Ceará.

Vale citar que em algumas instituições pesquisadas, trabalhos que utilizaram metodologias participativas de cartografia foram desenvolvidos em outros programas de mestrado e doutorado fora da área da Geografia, como a Antropologia que tem trabalhado com esta temática tendo em vista o próprio legado do trabalho de antropólogos(as) ligados ao PNCSA.

Este é o caso da UEMA, que não obteve resultado positivo de trabalhos defendidos dentro da Geografia, até mesmo em função de ser um curso ainda recente, mas que, no entanto, a instituição dispõe de um programa de pós-graduação dedicado a esta temática: o Programa de Pós-Graduação em Cartografia Social e Política da Amazônia, vinculado ao Projeto Nova Cartografia Social da Amazônia, que apresenta uma expressiva quantidade de trabalhos na área.

Este também é o caso da Universidade do Estado de Pernambuco (UPE) que não oferta cursos de pós-graduação em Geografia, mas que possui um grupo de pesquisa também diretamente ligado ao projeto Nova Cartografia Social, denominado Laboratório de Estudos sobre Ação Coletiva e Cultura (LACC), coordenado pela Antropóloga Vânia Fialho. Este vem desenvolvendo projetos sobre práticas espaciais e mobilização política de povos e comunidades em Pernambuco, bem como tem sido o ambiente de produção de pesquisas acadêmicas $^{5}$ de mestrado e doutorado (no campo da Antropologia) envolvendo as experiências de mapeamento. É um ponto de convergência de demandas de povos indígenas, quilombolas e grupos urbanos que procuram o laboratório com objetivo de mapear seus territórios pela via da cartografia social. Recentemente publicou seu $3^{\circ}$ fascículo, este sobre o bairro de Santo Amaro em Recife (PIRES; FIALHO; ALMEIDA, 2016), destacando o tema da importância dos times de futebol na definição da identidade da população daquele local.

Retomando, quanto à questão dos temas, a leitura dos trabalhos levantados por esta revisão de literatura nos permitiu identificar a abordagem de temas variados por meio da

\footnotetext{
${ }^{4}$ O Labocart da UFC produzido vários artigos sobre o uso da cartografia participativa como metodologia nos trabalhos de geografia, inclusive àquelas mais ligados a dinâmicas ambientais e gestão de unidades de conservação. Algumas dessas experiências estão relatadas no livro: "Cartografia Social e Cidadania: experiências de mapeamento participativo dos territórios de comunidades urbanas e tradicionais" publicado em 2015.

${ }^{5}$ Para um panorama das pesquisas desenvolvidas pelo LACC e parceiros ver o artigo "Nova Cartografia Social: experiências metodológicas e dinâmicas territoriais no Nordeste do Brasil" de NEVES et al (2015), bem como os fascículos disponíveis no site do Projeto Nova Cartografia social http://novacartografiasocial.com/ 
Cartografia participativa que corresponderam aos seguintes: Invisibilidade social, Preservação do patrimônio arquitetônico, Impactos Socioambientais em territórios comunitários, Política ambiental urbana, Habitabilidade e produção do espaço urbano, Políticas públicas para mulheres e ensino de Geografia.

É interessante observar a apropriação das metodologias de cartografia participativa no tratamento de temas clássicos da pesquisa geográfica como a produção do espaço urbano e a discussão das políticas públicas. Por outro lado, percebe-se que a Cartografia Participativa traz consigo, enquanto metodologia, a necessidade de pensar a afirmação de identidades territoriais coletivas envolvidas nos diferentes processos espaciais estudados, conforme já é observado nas experiências na Amazônia desenvolvidas pelo PNCSA, e que em nosso conjunto de dados pode ser representado por dois casos: a dissertação que versa sobre a invisibilidade social de indígenas da Província de Buenos Aires e também o trabalho que trata de formas de pensar a preservação do patrimônio de Igarassu. Estes são, como se sabe temas abordados mais recentemente na pesquisa geográfica.

Em termos de área de estudo, no total das 10 pesquisas realizadas, 4 propõem a utilização da cartografia participativa em ambientes eminentemente urbanos, como a proposta desenvolvida na dissertação sobre a relação entre gestores e conselheiros da gestão ambiental urbana em Mossoró (RN), bem como o trabalho sobre habitabilidade no bairro de Pirajá na periferia da cidade de Salvador. Isso corrobora com as proposições de que a cartografia deve ser cada vez mais reapropriada pela geografia como uma linguagem e uma técnica que pode ser utilizada a partir de diferentes abordagens teórico-metodológicas (Matias,1996; Girardi,2011), significando a superação de um posicionamento reativo ao uso da Cartografia pelos geógrafos que tratam de temas da geografia humana relatada por Souza e Katuta (2011) para as décadas de 1980 e 1990. Nesse sentido, a Cartografia participativa parece ser uma das formas interessantes de retomada do campo da cartografia pela Geografia humana.

Por outro lado, a maioria dos trabalhos teve como área de estudo territórios de comunidades situadas em áreas rurais ou fora de grandes cidades, sendo: um dos trabalhos desenvolvido em território quilombola, outro, em território indígena, três em comunidades pesqueiras. Com base nesse panorama podemos observar que permanece uma certa tendência no emprego desta metodologia no âmbito de povos tratados comumente como tradicionais e que se localizam fora dos grandes centros urbanos, seguindo aquilo que foi descrito por Acserald e Coli $(2008 ; 2013)$ sobre a origem da cartografia participativa no âmbito da criação e gestão de áreas protegidas e unidades de conservação. 
Constatou-se que todos os dez trabalhos discutiram o mapeamento participativo muito mais nos tópicos referente a metodologia da pesquisa, dentre as possibilidades de terem sido enfocados em outros momentos como a introdução, na definição de tema e objetivos ou como parte do referencial teórico. Isso demonstra que a Cartografia Participativa tem sido encarada, nestes trabalhos de Geografia, mais como um procedimento metodológico do que como tema central ou objeto ela mesma de análise. Em 3 dos trabalhos -a dissertação em Ciências Geodésicas da UFPE; a que trata das Visões Cartográficas de Itabaiana (SE) e a dissertação sobre os problemas ambientais sobre a reserva Canto Verde, no Ceará, foram as que, segundo nossa leitura, deram mais destaque a reflexão sobre a cartografia participativa em outras etapas do relatório da pesquisa além da metodologia: a cartografia aparece também na discussão do referencial teórico e nas considerações finais.

É importante ressaltar que, durante a busca nos bancos de pesquisa, verificou-se que as expressões "cartografia participativa ou social” muitas vezes não estavam contidas no título ou no assunto. Mesmo quando havia no conteúdo do trabalho a denominação desta metodologia adotada. $\mathrm{O}$ inverso também ocorreu, pois foram encontrados casos em que o resumo da dissertação citou-se o termo "mapeamento", ou termos correlatos como "diagnóstico participativo" dentre as ações dos procedimentos metodológicos, mas a leitura da metodologia levantou questionamentos sobre a forma realização da cartografia participativa pois o passo a passo não havia sido detalhado. Nesse sentido, acredita-se que a não inserção da cartografia participativa e termos correlatos entre as palavras-chave, bem como as descrições resumidas das formas de se fazer os mapeamentos pode indicar ainda a pouca visibilidade dada a esse recurso metodológico dentro das pesquisas em Geografia, ou mesmo, por outro lado a carência de uma maior discussão teórica e delineamento metodológico dentro da academia, para que os pesquisadores possam se apoiar nesta ferramenta com maior propriedade, conforme indica Landim Neto et al (2016).

No que concerne às formas de se fazer cartografia, pôde-se observar que houve pesquisas que envolveram ferramentas específicas da técnica, como o GPS, SIG, programas de elaboração de mapas, plataformas de mapas online como o Google Earth e que as mesmas foram inseridas no processo participativo, isto é, tentou-se na maioria das pesquisas envolver a população informante. Essa participação nas metodologias de cartografia se deu de diferentes formas, desde oficinas com discussão em grupo para geração de diagnóstico nas quais os grupos apontamento da localização dos fenômenos/problemas em foco em mapas impressos no papel, até mesmo o relato da inserção dos grupos participantes no mapeamento 
dos territórios por meio de caminhamentos em campo com GPS. Em um caso específico, no trabalho "A etnoecologia de pescadoras e as políticas públicas em Bom Jesus dos Pobres", o pesquisador optou por incluir os participantes na confecção direta dos mapas com a utilização de software ArcGis 10.1 para mapeamento, a construção do que ele denominou EtnoSIG (Araújo, 2015, p. 84-85).

\section{CONCLUSÃO}

A partir desse levantamento da produção de dissertações e teses na área da Geografia nos programas de pós-graduação do Nordeste brasileiro, foi possível compor uma base material para refletirmos sobre a importância do papel dessa metodologia participativa na pesquisa geográfica. Nesse sentido, a observação do uso da cartografia participativa em 9 pesquisas de mestrado e uma de doutorado, ainda que pouco numerosa, nos parece ser indicativa de uma abertura crescente à inserção dos grupos sociais no desenvolver dos trabalhos.

As experiências aqui retratadas demonstram a busca por ferramentas que sejam ao mesmo tempo parte dos procedimentos metodológicos viabilizando o alcance dos objetivos do trabalho acadêmico, mas que também, por outro lado, possam funcionar de maneira mais ampla como instrumentos de mobilização política das populações em torno de suas próprias demandas.

De acordo com os relatos das pesquisas levantadas, o resultado do uso do mapeamento participativo no âmbito dessas dissertações e teses levantadas não foge à regra do que tem sido observado para o uso desta metodologia em outros campos de estudo além da Geografia (Acserald (2008) Acserald; Viégas(2013) pois na maioria dos trabalhos analisados a cartografia participativa contribuiu para ampliação da visão dos pesquisadores sobre tratamento dos variados temas das pesquisa (desde a invisibilidade social até a preservação do patrimônio) pela consideração e apropriação no trabalho da ótica dos grupos que vivem nos territórios estudados, sejam unidades de conservação ou bairros periurbanos para nos remeter ao universo de pesquisas.

Essa aproximação entre o pesquisador atento às demandas dos sujeitos, que conhecem seus territórios e tem para estes um projeto, resulta em trabalhos que ressaltam conflitos político-territoriais existentes, bem como traz para o registro das pesquisas os dilemas sobre os processos de decisão por que passam as populações que estão no foco das pesquisas. É 
desssa maneira, que, conforme coloca Landin Neto et all (2016) a opção metodológica pela cartografia participativa - fundamentada nos princípios da "investigação-ação-participação"conduz o pesquisador a destacar em seu trabalho aspectos do espaço ressaltados primeiramente pelos grupos participantes da pesquisa.

Sobre o levantamento, vale lembrar que houve algumas limitações técnicas envolvidas nas buscas como a falta de atualização nas páginas oficiais dos programas de pós-graduação, a sistematização de palavras-chave, e, inclusive, a não utilização dos termos referentes ao recurso metodológico nos campos destinados para busca on line (título, resumo, palavrachave, área). Dessa forma, houve a dificuldade de acessar mais trabalhos que possam existir, mas que ainda não estejam disponíveis por estes mecanismos utilizados neste levantamento

Pensar este trabalho da maneira como foi realizado, ou seja, a partir de um levantamento de literatura por meio de bases digitais de busca do que vem sendo produzido dentro da pós-graduação em Geografia na região Nordeste, é uma oportunidade, portanto, de apresentar os resultados ao público interessado nesta temática. Também é uma forma de refletir sobre as contribuições da cartografia participativa em diversos âmbitos da geografia e, por conseguinte, nas suas aplicações em diversos contextos sociais. Esperamos em breve poder ampliar este levantamento incluindo novos trabalhos acadêmicos sobre essa metodologia participativa e seus rebatimentos teóricos para a pesquisa geográfica.

\section{REFERÊNCIAS}

ACSERALD, Henri. Introdução e $1^{\circ}$ artigo. In: ACSERALD, H (Org). Cartografias sociais e território. Rio de janeiro: UFRJ/IPPUR, 2008.

ACSELRAD, H; VIÈGAS, R. N. Cartografias Sociais e Territórios - um diálogo latino americano. In: Cartografia Social, terra e território. ACSELRAD, H; VIÈGAS, R. N, et al (Orgs). Universidade Federal do Rio de Janeiro, Instituto de Pesquisa e Planejamento urbano e Regional, 2013, 318p.

ANDRADE, Érica Delania de. A elaboração de documentos cartográficos sob a ótica do mapeamento participativo. 2008. 78 f. Dissertação (Mestrado) - Curso de Programa de Pósgraduação em Ciências Geodésicas e Tecnologias da Geoinformação, Departamento de Engenharia Cartográfica, Universidade Federal de Pernambuco, Recife, 2008. Disponível em: $<$ http://repositorio.ufpe.br:8080/bitstream/handle/123456789/3083/arquivo2058_1.pdf?seque nce $=1$ \&isAllowed=y $>$. Acesso em: 1 ago. 2017. 
ANDRADE, E.; CARNEIRO, A. F. T. A elaboração de documentos cartográficos sob a ótica do mapeamento participativo. In: Boletim de Ciências Geodésicas, América do Norte, 15, set. 2009. Disponível em: http://ojs.c3sl.ufpr.br/ojs2/index.php/bcg/article/view/15506/10357. Acessado em: 05 Ago. 2013.

ARAUJO, Regys Fernando de Jesus. A etnoecologia de pescadoras e as políticas públicas em Bom Jesus dos Pobres, Saubara - BA. 2015. 148 f. Dissertação (Mestrado) - Curso de Programa de Pós-graduação em Planejamento Territorial - Planterr/uefs, Universidade Estadual de Feira de Santana, Feira de Santana, 2015.

ARCHELA, Rosely Sampaio. Cartografia contemporânea e novas tecnologias. In: ARCHELA, R. S.; FRESCA, T. M; SALVI, R F. (org). Novas Tecnologias. Londrina: Ed UEL, 2001.

ARCHELA, Rosely Sampaio; ARCHELA, Edison. Correntes da Cartografia teórica e seus reflexos na pesquisa. Geografia. Londrina. v 11, n. 2, 2002. (p. 161- 170)

CARVALHO, Mariano de Oliveira. Cartografia participativa e planejamento urbano: experiências de práticas colaborativas no ambiente escolar em Campos Sales, Ceará. 2016. 166 f. Dissertação (Mestrado) - Curso de Mestrado Acadêmico em Geografia (mag), Universidade Estadual Vale do Acaraú (uva), Sobral, 2016. Disponível em: $<$ http://uvanet.br/mag/documentos/dissertacao_da8dbaa4a2da2f47a621746c6b461c31.pdf $>$.

Acesso em: 1 ago. 2017

COSTA, Nátane Oliveira da. Cartografia social: instrumento de luta e resistência no enfrentamento dos problemas socioambientais na reserva extrativista Marinha da Prainha do Canto Verde, Beberibe - Ceará. 2016. 157 f. Dissertação (Mestrado) - Curso de Programa de Pós-graduação em Geografia, Universidade Federal do Ceará, Fortaleza, 2016. Disponível em: <http://www.repositorio.ufc.br/handle/riufc/21447>. Acesso em: 1 ago. 2017.

CRAMPTON; KRYGIER. (2006) Introdução a uma cartografia Crítica. In: Cartografias Sociais e Território, 2008. p.85-111 (trad. Carolina Apolinário de Souza)

GIRARDI, Eduardo Paulon. A construção de uma Cartografia geográfica crítica. Revista Geografica de America Central (online), v. 2, p. 2019-4758-1-SM, 2011. Disponível em $<$ http://www.revistas.una.ac.cr/index.php/geografica/article/viewFile/2019/1918>. Acessado em 27 de junho de 2014 as $23 \mathrm{~h} 53 \mathrm{~min}$.

HARLEY, J. B. Deconstructing the map. Canadá: Cartographica, 1989.

HARLEY, Brian. Mapas, saber e poder. IN: Confins [Online], 5 | 2009. Disponível em: $<$ http://confins.revues.org/5724>. Acesso em 02 de Março de 2013, às 00h:02m. 
FERREIRA, A. C. S.; CARNEIRO, A. F. T.; PAIXÃO, S. NICHOLS, S. Ciências Geodésicas num contexto social ampliado. In: Anais do II Simpósio Brasileiro de Ciências Geodésicas e Tecnologias da GeoInformação. Recife, 2008. Disponível em: $<$ http://www.ufpe.br/cgtg/SIMGEOII_CD/Organizado/cad/103.pdf $>$. Acesso em: 05 de maio 2013.

FONSECA, Fernanda Padovesi. A inflexibilidade do espaço cartográfico, uma questão para a geografia: análise das discussões sobre o papel da Cartografia. 2004. 250f. Tese (Doutorado em Geografia Física) - Universidade de São Paulo, São Paulo, 2004. Disponível em: $\quad<$ http://www.teses.usp.br/teses/disponiveis/8/8135/tde-09082010-130954/pt-br.php>. Acessado em 03 de Abril de 2014 às 19 h.

GORAYEB, A.; Meireles, A. J. de A. (Org.) ; SILVA, E. V. (Org.). Cartografia Social e Cidadania: experiências de mapeamento participativo dos territórios de comunidade urbanas e tradicionais. 1. ed. Fortaleza: Expressão Gráfica, 2015. 196p

LANDIM NETO, F. O. ; SILVA, E. F.; COSTA, N. O. Cartografia Social instrumento de construção do conhecimento territorial: Reflexões e proposições acerca dos Procedimentos Metodológicos do Mapeamento Participativo. In: Revista Casa da Geografia de Sobral. Número especial sobre o V Congresso Brasileiro de Educação Ambiental Aplicada à Gestão Territorial, v. 18, n. 2, p. 56-70, Set. 2016, http://uvanet.br/rcgs. ISSN 2316-8056.

LUCHIARI, Ailton; KAWAKUBO, Fernando S.; MORATO, Rúbia G. Aplicações do sensoriamento remoto na Geografia. In: VENTURI, L. A.B. (org.). Praticando a geografia: técnicas de campo e laboratório em geografia e análise ambiental. São Paulo: Oficina de textos, 2005, p. 33-54.

MATIAS, Lindo Fonseca. Sistema de Informações Geográficas (SIG): teoria e método para representação do espaço geográfico. Tese de Doutorado em Geografia. FFLCH/USP, São Paulo, 2001. 313p.

MATIAS, Lindo Fonseca. Por Uma Cartografia Geográfica - Uma Análise Da Representação Gráfica Na Geografia. Dissertação de Mestrado em Geografia. FFLCH/USP, São Paulo, 1996.

MENDES, Jocicléa de Sousa. Parques eólicos e comunidades tradicionais no Nordeste brasileiro: estudo de caso da Comunidade de Xavier, litoral oeste do Ceará, por meio da abordagem ecológica/participativa. 2016. 160 f. Tese (Doutorado em Geografia) Universidade Federal do Ceará, Fortaleza, 2016. 
MONMONIER, M. S. How to lie with maps. Chicago: The University of Chicago Press, 1996

NEVES, Rita de Cássia Maria et al. Nova Cartografia Social: experiências metodológicas e dinâmicas territoriais no Nordeste do Brasil. In: CONGRESSO INTERNACIONAL DE AMERICANÍSTICA, 37., 2015, Perugia. Thule - Rivista italiana di studi americanistici. N 38/39-40/41. Perugia: Centro Studi Americanistici "circolo Amerindiano" Onlus, 2017. p. 613 - 633. Disponível em: <www.amerindiano.org>. Acesso em: 24 ago. 2017

OLIVEIRA, Luan Gomes dos Santos de. Atores sociais e política ambiental urbana do Município de Mossoró/RN pelo prisma das cartografias sociais analíticas. 2012. $143 \mathrm{f}$. Dissertação (Mestrado em Meio Ambiente, Cultura e Desenvolvimento) - Universidade Federal do Rio Grande do Norte, Natal, 2012.

PANIZZA, A. C, FONSECA, P. D. Técnicas de interpretação visual de imagens. GEOUSP Espaço e Tempo, São Paulo, n. 30, p. 30-43, 2011.

PIRES, Maria Jaidene; FIALHO, Vânia; ALMEIDA, Alfredo Wagner Berno de. Times de Futebol do Bairro de Santo Amaro, Recife-PE. Manaus: UEA Edições/ UPE, 2016. 16 p. (Coleção Direitos e Identidades). Nova cartografia social dos povos e comunidades do Brasil. ROSA, R. (2005). Geotecnologias na Geografia Aplicada. Revista do Departamento de Geografia, v. 16, p. 81-90.

REBOUÇAS, Fádia dos Reis. Moradia e habitabilidade no bairro de Pirajá no contexto da produção do espaço urbano periférico da cidade de Salvador-BA. 2011. 181 f. Dissertação (Mestrado) - Curso de Programa de Pós-graduação em Geografia (posgeo), Instituto de Geociências, Universidade Federal da Bahia, Salvador, 2011. Disponível em: $<$ https://repositorio.ufba.br/ri/handle/ri/17797?mode=simple\&submit_simple=Mostrar+registr o+simples+do+item>. Acesso em: 2 ago. 2017

ROSSO, Inés. Por uma geografia da (in)visibilidade: cartografia social e luta pelo reconhecimento indígena na Província de Buenos Aires/Argentina. 2017. 156f. Dissertação (Mestrado em Geografia) - Centro de Ciências Humanas, Letras e Artes, Universidade Federal do Rio Grande do Norte, Natal, 2017.

SANTOS, Jadson de Jesus. Visões cartográficas de Itabaiana-SE. 2014. 104 f. Dissertação (Mestrado em Desenvolvimento e Meio Ambiente) - Universidade Federal de Sergipe, São Cristóvão, 2014.

SILVA, Cláudio Antônio Vieira da. Mudanças e permanências na paisagem do sítio de Igarassu/PE. 2014. 214 f. Dissertação (Mestrado) - Curso de Programa de Pós-graduação em 
Desenvolvimento Urbano, Centro de Artes e Comunicação, Ufpe, Recife, 2014. Disponível em: <http://repositorio.ufpe.br/handle/123456789/17076>. Acesso em: 1 ago. 2017.

SOUZA, José Gilberto de; KATUTA, Ângela Massumi. Geografia e conhecimentos cartográficos. In: SOUZA, José Gilberto de; KATUTA, Ângela Massumi. A Cartografia no movimento de renovação da geografia brasileira e a importância do uso de mapas. São Paulo: Editora Unesp, 2001.

TAYLOR. F. Uma Base Conceitual para a Cartografia: Novas Direções para a Era da Informação. Caderno de Textos - Série Palestras, São Paulo, v. 1, n.1, p. 11-24, ago, 1994. 